\title{
ConsideraÇões SOBRE A ATUALIDADE DA FORMAÇÃO CULTURAL/EDUCACIONAL: NOVOS DESAFIOS PARA A PESQUISA*
}

\author{
Considerations on the current status of cultural/educational \\ formation: new challenges for research
}

RESUMO O presente texto visa traçar alguns contornos do que compreendo ser o pano de fundo atual para possíveis investigações que versem sobre a formação cultural/educacional brasileira sob a ótica da Teoria Crítica. À luz desse traçado, pretendo apresentar as duas vertentes temáticas de pesquisa as quais, mais recentemente, figuram como objetivos centrais do projeto de pesquisa que desenvolvo no Departamento de Psicologia da Educação da Faculdade de Ciências e Letras da Unesp de Araraquara. Nomeadamente se trata de compreender a deformação interna que sofre a própria formação como substância concreta do processo de ensino levado a cabo em estabelecimentos escolares. Para tanto, se faz necessário investigar empiricamente como os esquemas da indústria cultural se tornam presentes na cena didático-pedagógica. E, de outra parte, a elucidação desse problema requer uma investigação teórica do processo mais amplo de constituição da subjetividade hodierna sob o impacto dessa mesma indústria. Ambos os objetivos aqui enunciados visam fornecer subsídios para efetuar leituras possíveis a respeito das "novas demandas educacionais" no Brasil.

PalaVRas-chaVe EdUCAÇão; CUltura; teoria CRÍtica.

ABstract This paper aims to draw some outlines of what I understand to be background for possible investigations that examine the cultural / educational problems in Brazil from the perspective of Critical Theory. Under the light of these outlines I intend to present two directions of research which are the main objectives of the research project I develop within the Department of Educational Psychology of College of Sciences and Letters of Unesp in Araraquara. In particular, it is necessary to understand the internal deformation that education suffers as a concrete substance of the teaching process in schools, which makes an empirical investigation how the cultural industry's schemes become present in the "didactic pedagogical scene" necessary. On the other hand, the elucidation of this problem requires a theoretical investigation about the broader process of constitution of today's subjectivity under the impact of that industry. Both goals set forth herein are intended to provide subsidies to make readings about new educational demands possible in Brazil.

\section{KEYWORDS EDUCATION; CULTURE; CRITICAL THEORY.}

* Uma versão modificada deste texto foi apresentada na $34^{\mathrm{a}}$ Reunião Anual da Associação Nacional de Pós-Graduação e Pesquisa em Educação (ANPED), realizada em outubro de 2011, em Natal, Rio Grande do Norte.

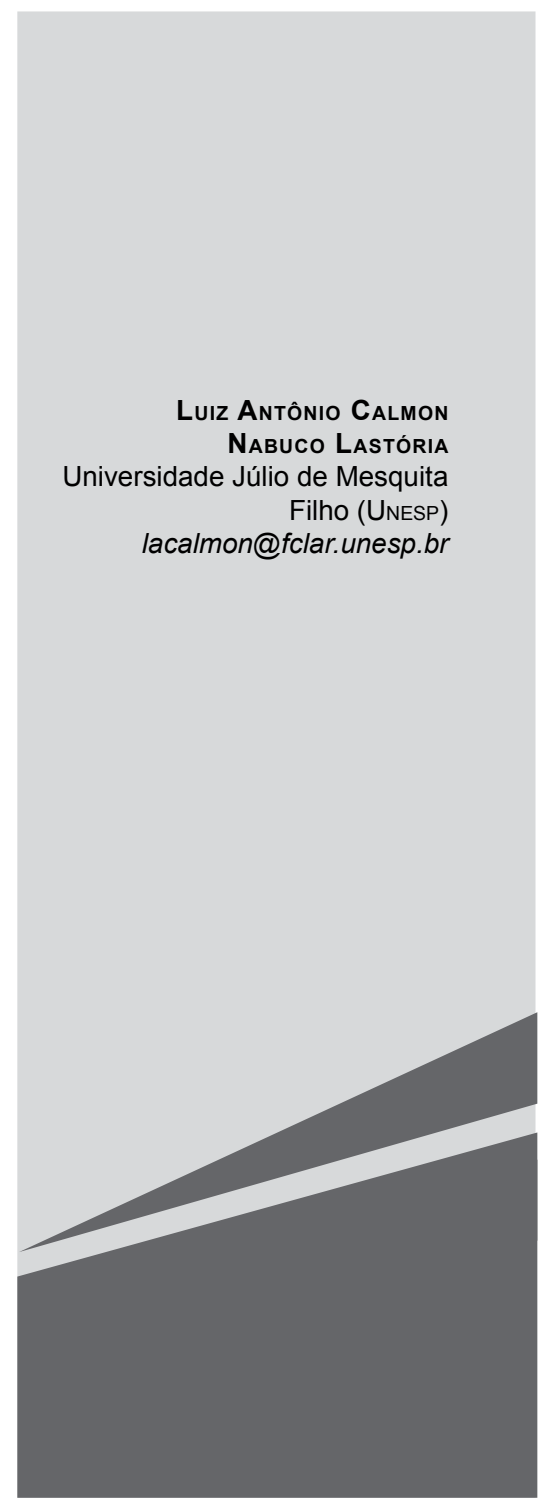


C omo é sabido, a ideia de Bildung foi cultivada em solo alemão ${ }^{1}$. Trata-se de uma noção perfilada a partir da releitura da antiguidade clássica efetuada pelos intelectuais alemães, com intuito de ancorar a identidade do povo germânico quando da unificação do império austro-húngaro. Eivada de uma forte carga idealista, essa ideia serviu de fio condutor da produção intelectual germânica, expressando-se, sobretudo, por intermédio das obras literárias e filosóficas desde o final do século $\mathrm{XVIII}^{2}$. Não obstante o escrutínio da noção de Bildung tenha sido levado a cabo por diversos críticos, e, talvez, de forma mais radical pelo pensamento de Friedrich W. Nietzsche, foi Theodor W. Adorno quem a reconsiderou se servindo do procedimento da negação determinada próprio ao pensamento dialético de extração hegeliana. Desde então, observar a sociedade no decorrer de seu desenvolvimento histórico rastreando os indícios dos processos de dominação aí incrustados, com vistas a esquadrinhá-los sob o prisma da crítica, constituiu o imperativo maior da assim chamada Teoria Crítica da Sociedade ${ }^{3}$.

1 A esse respeito são concisas as palavras de Rose (2007), em seu livro O Misterioso Caso Alemán: um intento de comprender Alemania a través de sus letras: "Que la identidad colectiva alemana se definiera tan obcecadamente por la armonía y el amor al ideal - estrechamente relacionados com El concepto neohumanista de Bildung [...] - sin duda la ha enoblecido y le ha permitido construir uma identidad nacional imaginaria, pero sólida." [...] "El ideal de Bildung era un ideal de ideales: La búsqueda consciente de lo verdadero, lo bueno y lo bello. No obstante, estaba dotado de uma naturaleza pseudorreligiosa, lo que lo volvía débil [...]”.

2 Ainda que se tratasse de ideal considerado ingênuo perante a crítica, a noção de Bildung encerrava algo de [...] inusitadamente hermoso, y cuya enorme y sorprendente proyección debemos los mejores frutos que nos há dado Europa em los últimos siglos. Em realidad, es mucho más que eso: se trata del ideal alemán por excelência, aquel sobre el que se asientan o en el que tienen cabida todos los demás. Bildung es, en definitiva, la columna vertebral del idealismo alemán” (ROSE, 2007, p. 74).

3 No tocante ao desenvolvimento nuclear das ideias que vieram consubstanciar a chamada Teoria Crítica da Sociedade, é preciso ter presente que o conceito de Bildung não apontou, ao menos inicialmente, para preocupações próprias ao âmbito educacional. Nesse sentido, cabe registrar que o conceito de "indústria cultural", por exemplo, foi originalmente formulado por Horkheimer e Adorno (1985) de modo alheio às preocupações educacionais, e que o conceito de semicultura, tal como utilizado por Adorno (2010) em suas reflexões sobre educação, já se encontrava no pensamento educacional alemão de F. Paulsen desde 1903.
Ao longo dos últimos anos, e em parceria com todos os demais pesquisadores integrantes do Grupo de Estudos e Pesquisa (GEP) Teoria Crítica e Educação, venho me dedicando à investigação de duas grandes vertentes temáticas, as quais, mais recentemente, figuram como objetivos centrais do projeto de pesquisa que desenvolvo no Departamento de Psicologia da Educação da Faculdade de Ciências e Letras da Universidade Estadual Paulista "Júlio de Mesquita Filho" (Unesp) de Araraquara. Nomeadamente se trata de compreender a deformação interna que sofre a própria formação como substância concreta do processo de ensino levado a cabo em estabelecimentos escolares. Para tanto, se faz necessário investigar empiricamente como os esquemas da indústria cultural se tornam presentes na cena didático-pedagógica. E, de outra parte, a elucidação desse problema requer uma investigação teórica acerca do processo mais amplo de constituição da subjetividade hodierna sob o impacto dessa mesma indústria na era da chamada "cultura digital". Vistos contra o pano de fundo estabelecido pelas investigações empreendidas no âmbito da educação brasileira, ambos os objetivos aqui enunciados visam fornecer subsídios para efetuar leituras possíveis acerca das "novas demandas educacionais" ${ }^{4}$, que, de acordo com a minha hipótese central, nada mais são do que novas formas de tradução racionalizada do problema concreto do fracasso escolar presente há décadas em nosso País.

$\mathrm{Na}$ impossibilidade de realizar uma exposição sistemática acerca dos resultados obtidos ao longo desses últimos anos no que se refere aos dois objetivos acima mencionados, restrinjo-me apenas ao esboço de alguns contornos do que compreendo ser o background, ou as linhas mestras atuais para possíveis investigações que versem sobre a formação cultural/educacional brasileira sob a ótica da Teoria Crítica.

Tomemos o problema da formação no sentido restrito ao chamado período de escolarização. Como se sabe, a produção do fracasso escolar,

4 Sob o impacto do desenvolvimento tecnológico exponencial sobre a totalidade do tecido sociocultural, tal como verificado nas últimas décadas, velhos problemas como indisciplina, avaliação, motivação, e mesmo alfabetização, dentre outros, assumiram formas outras, de modo a configurar novas demandas no plano da educação. 
presente há décadas na história da educação brasileira, consiste num fenômeno multideterminado e sobre o qual muito já se falou. Investigações voltadas ao problema, e atentas ao cotidiano das instituições escolares, evidenciam demandas enfrentadas no âmbito educacional hodierno envolvendo seus diferentes níveis - desde a formação cultural dos professores até os problemas relativos às dificuldades de aprendizagem dos alunos, passando pelas consequências advindas das políticas educacionais no País.

Mas foi somente a partir de 1996, no entanto, que as novas diretrizes educacionais por meio dos Parâmetros Curriculares Nacionais (PCNs), instituídos conforme a Lei de Diretrizes e Bases da Educação Nacional (LDB) - Lei no 9.394, de 17 de dezembro de 1996, tornaram-se uma realidade efetiva no Brasil, inaugurando um novo cenário que passou a requerer especial atenção de inúmeros estudiosos e especialistas. Autores como Gentili (1995) e Chauí (1999) foram enfáticos ao mostrarem como esse novo cenário edificou-se a partir do receituário prescrito pelo Banco Mundial para o âmbito da educação. Além disso, diversos estudiosos têm procurado focar suas avaliações ora no esclarecimento das contendas políticas resultantes das correlações de forças exercidas por diversos grupos sociais, sobretudo quando do estabelecimento da nova LDB, ora na crítica dos pressupostos ideológicos embutidos nas orientações educacionais contidas nos PCNs dela decorrentes, os quais se desdobram no âmbito pedagógico concreto 5 .

Não obstante o teor por vezes bastante elucidativo dessas diferentes perspectivas de avaliação, uma questão crucial para o esclarecimento do problema que se discute permanece obscura a meu ver: trata-se exatamente do que se convencionou chamar genericamente por "crise cultural". Para alguns, "crise de valores", para outros, "crise de paradigmas". Tal como fora observado por Adorno (2010) em sua Teoria da Semiformação, constata-se, de imediato, a persistência de "uma inocente despreocupação frente ao poder

\footnotetext{
A esse respeito, remeto o leitor para o ilustrativo artigo de Marília G. de Miranda "Pedagogias Psicológicas e Reforma Educacional”. In: DUARTE, N. (Org.) 2000a. Sobre o Construtivismo. Autores Associados, Campinas - SP., p. 23-40.
}

que a realidade extrapedagógica" exerce sobre as práticas educacionais em curso, realidade essa que não se deixa esgotar pelo mapeamento das contendas verificadas no âmbito político, ou mesmo pela crítica ideológica aos pressupostos pedagógicos, e que requer a construção de "uma teoria que seja abrangente" .

Independente da denominação que se adote para adjetivar a referida crise, uma perspectiva sóbria quanto aos rumos da educação brasileira, particularmente nas últimas duas décadas, deve levar em consideração os drásticos efeitos decorrentes do paulatino deslocamento "geológico" da infraestrutura da sociedade sobre os fenômenos superestruturais, ensejando o que venha a ser a indústria cultural contemporânea. Já em meados do século passado, Hanna Arendt (1988) chamou a atenção para esse fato, ao tecer considerações sobre o panorama educacional norte-americano daquele período. Arendt não apenas distinguiu a cultura stricto sensu da indústria do entretenimento, como também chamou a atenção para a ruína da noção de autoridade e de seus subprodutos em nível das interações geracionais.

Mas, como se sabe, foram Max Horkheimer e Adorno quem, em 1947, cunharam o conceito de "indústria cultural" com o intuito de refinar o diagnóstico das relações de dominação sob o capitalismo avançado. No célebre texto sobre a "indústria cultural" publicado na Dialética do Esclarecimento, Horkheimer e Adorno analisaram alguns produtos culturais como músicas, especialmente o jaz\%, novelas, cinema hollywoodiano, dentre outros, do ponto de vista de sua constituição objetiva. Concluíram que a produção em série da cultura voltada para as massas de consumidores distribuídos em gradientes de mercado sofre um brutal empobrecimento. As fórmulas comerciais gastas que induzem ao fun tornam-se a tônica da produção cultural, a relação dialética frouxa entre o detalhe e o todo na composição formal das obras de arte as despotencializam, e a produção obedece ao que eles chamaram de círculo de manipulação da necessidade retroativa, isto é, cada novo produto cultural deve apelar à subjetividade do consumidor como se respondesse ao seu desejo preexistente.

ADORNO, 2010, p. 8.

ADORNO, 2010, p. 9. 
Também nesse contexto as pesquisas tendem cada vez mais a se confundirem com a publicidade e a propaganda.

Enfim, sob a regência do modo de produção capitalista se verifica, no plano da cultura, não apenas uma redução da "sociedade da sapiência" a "sociedade da informação", esta última decodificável em moldes estritamente behavioristas, mas também a torna convergente com a "sociedade do design". Particularmente no âmbito linguístico, verifica-se que a significação, "única função da palavra admitida pela semântica, consuma-se no sinal". E que esse "reforça-se com a rapidez com que os modelos lingüísticos são colocados em circulação de cima para baixo" ". Finalmente, na era da Internet, cada vez mais a linguagem conflui para formas icônicas em substituição ao próprio texto alfabético ${ }^{10}$.

Ora, com o advento das novas mídias, sobretudo a partir dos anos 90 do século passado no Brasil, a indústria cultural enquanto totalidade sistêmica não só adquiriu maior consistência e coesão internas, como também ampliou em muito o seu raio de abrangência econômico e social ${ }^{11}$. Atualmente, nos encontramos sob o império das tecnoimagens digitais que se propagam velozmente dentro e fora do espaço virtual, penetrando fundamentalmente os ambientes domésticos, escolares e profissionais de amplos setores da população mundial $^{12}$. A esse respeito, observa-se nos PCNs, e também em inúmeras práticas pedagógicas concretas, certa naturalização - senão apologia - quanto à interposição das últimas inovações

HORKHEIMER, e ADORNO, 1985, p. 154.

HORKHEIMER, e ADORNO, 1985, p. 154/5.

10 Sobre as tendências contemporâneas verificadas no plano do código alfabético, remeto o leitor para o provocativo artigo de C. Türcke, Hipertexto, publicado no livro $A$ Indústria Cultural Hoje (ZUIN, 2008). Nesse artigo, o autor sustenta a tese segundo a qual a revolução midiática do século XX atingiu em cheio o texto. E também para as instigantes reflexões de Vilem Flusser contidas, no livro Sociedade Codificada (2007), e de Charles Melman, no livro $O$ Homem sem Gravidade: goz̧ar a qualquer preço (2003).

11 A esse respeito, ver o contributivo estudo de Rodrigo Duarte publicado sob o título Teoria Crítica da Indústria Cultural (2003).

12 Estudos mais recentes sobre o impacto das tecnoimagens, em particular, e dos mass media, em geral, na conformação subjetiva contemporânea das novas gerações em escala planetária, podem também ser encontrados no livro $A$ Indústria Cultural Hoje (ZUIN, DURÃO e VAZ, 2008). tecnológicas nos processos de ensino-aprendizagem, agora denominadas "novas ferramentas de ensino".

Aos olhos da Teoria Crítica, porém, no instante mesmo em que a informação, genética ou digital, se tornou o conceito chave para a extração de mais-valia ${ }^{13}$, o emprego das novas tecnologias no âmbito do ensino está longe de se constituir numa simples "ferramenta" pedagógica, sobretudo se aliadas às pedagogias de inspiração construtivista, as quais demarcam a tônica dos novos parâmetros curriculares, cujo pressuposto seria o de facilitar tanto a pesquisa, quanto a construção do conhecimento por parte dos discentes, além de os colocarem em sintonia fina com a suposta realidade do nosso tempo. De outra parte, quando nos atentamos para os rumos da educação atual, constatamos que muitos professores formados já no contexto da crise da educação em curso no País, e que se estende ao longo de décadas, não conseguem mais ultrapassar a prescrição pedagógica segundo a qual o ensino deveria partir da realidade do aluno. Resulta dessa dupla constatação que a substância concreta do processo de ensino tende a ficar refém da mesma realidade que serviu como ponto de partida pedagógico, ao repor de maneira amplificada, desavisada e contínua a tralha cultural de toda a espécie já circulante na sociedade midiática atual. E, ao assim proceder, a escola termina por abdicar de sua função formativa destinada a ampliar os horizontes culturais dos alunos a partir de uma apropriação consequente e crítica do conhecimento universal sistematizado, tal como fora enfatizado por Lev S. Vygotsky (1984), na década de 1920.

Vista de uma perspectiva macrossocial, a chamada revolução tecnológica industrial (microeletrônica associada à informática, à microbiologia e à engenharia genética) permitiu acelerar numa escala sem precedentes a incorporação de capital morto ao processo produtivo. Assim, ao mesmo tempo em que se passou a demandar uma elevada qualificação para uma parcela cada vez menor de trabalhadores estáveis - aqueles que supervisio-

\footnotetext{
13 A respeito da centralidade do conceito de informação para o desenvolvimento global do sistema capitalista, remeto o leitor para a elucidativa pesquisa de Laymert Garcia dos Santos, publicada sob o título Politizar as Novas Tecnologias (2003).
} 
nam as máquinas inteligentes na cadeia produtiva -, cresceu o desemprego estrutural e a precarização das condições de trabalho. Vínculos temporários e aumento desmedido do mercado informal tornaram-se uma realidade para grandes contingentes de trabalhadores, inclusive para consideráveis parcelas do professorado.

Nesse contexto de desemprego estrutural e de precarização das condições de trabalho, o problema da qualidade da escolarização/formação para um número cada vez maior de pessoas atendidas pela ampliação das ofertas de educação incluindo-se a educação à distância (EAD) - não se coloca como tal para as políticas neoliberais, ou melhor, não se colocou de fato até o presente momento. Cabe, pois, a indagação: não foram exatamente as políticas neoliberais que apregoaram o mercado como agente autorregulador último das práticas sociais que se materializam na sociedade, de modo a engendrar uma realidade que excede o alcance de quaisquer políticas sociais outras, ainda que bem-intencionadas?

Concomitante à escalada das políticas neoliberais posta em marcha no final da década de 80 , verifica-se que as organizações transnacionais do capital, tais como o Fundo Monetário Internacional (FMI), o Banco para a Reconstrução e o Desenvolvimento (BIRD) e o Banco Mundial (BM) assumiram o papel de substituir o conceito de "capital humano", vigente na década de 1960, por "sociedade do conhecimento" e seus conceitos derivados: "qualidade total", "flexibilidade", "integração", dentre outros, a partir dos quais se buscou otimizar tempo, espaço e energia de modo a aumentar a produção e a qualidade dos produtos e, consequentemente, o nível de competitividade e a taxa de lucro. Assim, "eficiência" e "equidade", "cidadania" e "revolução tecnológica" passaram a constituir os vetores ideológicos que conferiram sentido às novas retóricas que sustentaram as reformas educacionais no País a partir dos anos 1990. A esse respeito comentou Gaudêncio Frigotto em seu artigo Os Delírios da Razão: crise do capital e metamorfose conceitual no campo da educação:

Ao depurarmos o discurso ideológico que envolve as teses da 'valorização humana do trabalhador', a defesa ardorosa da educação básica, que possibilita a formação do cidadão e do trabalhador polivalente, participativo, flexível, e, portanto, com elevada capacidade de abstração e decisão, percebemos que isto decorre da vulnerabilidade que o novo padrão produtivo, altamente integrado, apresenta. ${ }^{14}$

Diante do exposto, pode-se concluir com Adorno (1996) que, se o rumo possível da formação dos indivíduos na sociedade burguesa caminhou, desde a sua gênese, no sentido da especialização, hoje a tensão verificada entre autonomia e adaptação, característica que ainda lhe é constitutiva, pende muito mais para o lado desta última. Obviamente se pode alegar que os rumos da educação brasileira ao longo dos últimos quinze anos apontam para certos avanços em termos sociais, sobretudo no que diz respeito à incorporação de amplas parcelas da população pelo sistema educacional. Porém, quando nos detemos com maior cautela no exame desses rumos e os focalizamos sob as lentes de conceitos como os de "indústria cultural" e de "semiformação", de maneira articulada, observamos ainda algo que está para aquém dos alarmantes índices atuais de analfabetismo funcional, ou das formas explícitas de privatização verificadas no setor, ou mesmo da atual redução e fragmentação do conhecimento à informação. Verificamos como a totalidade do sistema educacional vai, paulatinamente, se consumando num mero apêndice da indústria cultural. E, como a utilização dos saberes cada vez mais reduzidos aos velozes fluxos de informação transmitidos em tempo real passa a ser norteada por critérios essencialmente pragmáticos e utilitários tendo em vista responder às exigências requeridas pela atual sociedade de mercado, o que, por sua vez, engendra um outro tipo de subjetividade que lhe é sintônica.

Visto de uma perspectiva crítica, não se pode negligenciar que tais fatores se conjugam de modo a perfilar o núcleo de uma suposta formação que se pretende "cidadã", visando um futuro bastante próximo. E, nesse sentido, aqueles sonoros apelos

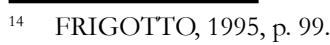


feitos à educação já no alvorecer do iluminismo europeu devem produzir novos ecos na contemporaneidade. Ao menos esse foi o intento de Adorno (1995) ao se referir às questões educacionais delineadas no horizonte do seu tempo mediante a formulação de um imperativo categórico negativo: o de que Auschwitz não viesse a se repetir. Conforme as suas palavras: "A exigência de que Auschwitz não se repita é a primeira de todas para a educação. De tal modo que ela precede quaisquer outras que creio não ser possível nem necessário justificá-la. Não consigo entender como até hoje mereceu tão pouca atenção" (ADORNO, 1995, p. 119).

Cônscio dos limites do esclarecimento, o filósofo cuidou de imprimir na elaboração do seu pensamento as marcas deixadas pela Shoah, catástrofe inominável cujo prenúncio o havia impelido ao exílio. Talvez o mais essencial a ser sublinhado nos dias atuais, especialmente quando refletimos acerca das práticas educacionais, em particular, e de todas as demais práticas formativas do presente, seja o fato de que muitas das condições históricas que ensejaram a morte de mais de 6 milhões de inocentes perduraram, dentre essas figura 0 irrefreável desenvolvimento das tecnociências atrelado ao inabalável processo de acumulação capitalista. Ora, na medida em que a totalidade do sistema educacional vai paulatinamente assumin- do a face de um mero apêndice da grande indústria da cultura do nosso tempo, tal como procuramos argumentar, ramo da indústria esse que se nutre em larga escala do desenvolvimento galopante da tecnologia, não estaríamos nos tornando mais vulneráveis a uma gama de atrocidades sociais bárbaras, todas elas vinculadas, sem dúvida, à educação e ao cultivo dos nossos hábitos?

Talvez, assim como a medicina tenha sido levada a considerar algumas enfermidades atuais de uma perspectiva multicausal, e, no limite, como expressão psicossomática de um modus vivendi, Auschwitz nos forneça apenas o padrão concentrado de inúmeras práticas sociais condenáveis do ponto de vista moral, e também político, que se espraiam pelo tecido social, diluindo-se até a irreconhecibilidade. Possivelmente, por essa mesma razão, Adorno (1995) tenha vinculado de modo tão enfático o seu imperativo categórico negativo à educação. Não obstante isso, nele o apelo às práticas educacionais traz em si a crítica daquelas pretensões iluministas próprias à Bildung do século XVIII, ou melhor, adquire contornos de uma prática social de resistência com a esperança de que ao menos aquelas catástrofes causadas por nós mesmos possam ser evitadas. Desse modo, urge aprofundar nossas reflexões sobre as questões relativas à semiformação em curso no Brasil, sobretudo ao longo das últimas duas décadas.

\section{REFERÊNCIAS}

ADORNO, T. W. Teoria da semicultura In: Revista de Ciências da Educação - Educação e Sociedade. Ano XVII, Dezembro, número 56. Cedes/Papirus: Campinas, 1996, p. 388-411.

. Educação e emancipação. Tradução de Wolfgang Leo Maar. São Paulo: Paz e Terra, 1995.

. Teoria da semiformação In: PUCCI, Bruno e LASTÓRIA, Luiz A. C. N. Teoria crítica e inconformismo: novas perspectivas de pesquisa. Campinas, Autores Associados, 2010, p. 7-40.

ARENDT, H. Entre o passado e o futuro. São Paulo: Perspectiva, 1988.

BRZEZINSKI, I. (Org.). LDB dez anos depois. Cortez: São Paulo, 2008.

CHAUÍ, M. A universidade operacional In: Caderno Mais, Folha de São Paulo, 9 de maio de 1999.

DUARTE, N. (Org.). Sobre o construtivismo. Autores Associados: Campinas, 2000a.

Vygotsky e o aprender a aprender - críticas às apropriações neoliberais e pós-modernas da teoria vigotskiana. Campinas: Autores Associados, 2000b. 
DUARTE, R. Teoria crítica da indústria cultural. Belo Horizonte: UFMG, 2003.

FRIGOTTO, G. Educação e crise do capitalismo real. Cortez: São Paulo, 1995.

FLUSSER, V. Sociedade codificada. Tradução Raquel Abi-Sâmara. Rio de Janeiro: Cosac Naify, 2007. GENTILI, P. (Org.). Pedagogia da exclusão. Vozes: Petrópolis, 1995.

. Adeus à escola pública In: GENTILI, P. (org.) Pedagogia da exclusão - crítica ao neo-liberalismo. Petrópolis - RJ: Vozes, 1995, p. 228-270.

GRUSCHKA, A. "Escola, didática e indústria cultural" In: DURÃO, F., ZUIN, A. e VAZ, Alexandre F. (Org.). A indústria cultural hoje. Boitempo: São Paulo, 2008, p.173-183.

HORKHEIMER, M; ADORNO, T. W. Dialética do esclarecimento. Tradução Guido Antonio de Almeida. Rio de Janeiro: Jorge Zahar Editor, 1985.

MELMAN, C. O Homem sem gravidade: gozar a qualquer preço. Tradução: Sandra Regina Felgueiras. Rio de Janeiro: Companhia de Freud, 2003.

ROSE, R. S. O Misterioso caso alemán: Um intento de comprender Alemania a través de sus letras. Barcelona: Alba Editorial, 2007.

SANTOS, L G. 2003. Politizar as novas tecnologias. São Paulo: Editora 34, 2003.

PUCCI, B. (Org.). Teoria Crítica e Educação. Vozes: Petrópolis, 1995.

VYGOTSKY, L. S. A Formação Social da Mente. Martins Fontes: São Paulo, 1984.

ZUIN, A. A. S., Durão, F. A., Vaz, A. F. indústria cultural hoje. São Paulo: Boitempo, 2008.

Dados do Autor

Doutor em Psicologia pela USP-SP;

pesquisador associado ao GEP Teoria Crítica e Educação (CNPq);

Professor Assistente Doutor

Departamento de Psicologia da Educação da Faculdade de Ciências e Letras

UNESP/Araraquara/SP

Recebido: 16/9/2011

Aprovado: 31/10/2011 